\title{
RESUMO
}

\section{A NOÇÃO DE GÊNERO NOS LIVROS DIDÁTICOS DE SOCIOLOGIA PARA O ENSINO MÉDIO}

\section{THE NOTION OF GENDER IN THE SOCIOLOGY TEXTBOOKS AT HIGH SCHOOL}

\section{LA NOCIÓN DE GÉNERO EN LOS LIBROS DE TEXTO DE SOCIOLOGÍA EN LA ESCUELA SECUNDARIA}

Renato Kendy Hidaka ${ }^{1}$ Gabriela Sebba Abdo ${ }^{2}$

\section{DOSSIÊ:}

"CORPO, GENNEROE SEXUALIDADE NA CIBERCULTURA: MODOSDE CONHECER, PRÁTICAS DE SOCIABILIDADEE REDES EDUCATIVAS"
Este artigo analisa o modo como a noção de gênero é tratada nos livros didáticos de Sociologia para o ensino médio aprovados pelo Programa Nacional do Livro Didático (PNLD) para o triênio de 2015-2017. Mais precisamente, norteiam o trabalho questões como: a noção de gênero está presente enquanto conteúdo nos livros didáticos? Caso a resposta seja positiva, ela aparece relacionada à temáticas específicas? Quais são os referenciais teóricos utilizados nos livros para fundamentar a abordagem do tema? Há diferentes formas de tratamento ou verifica-se uma homogeneidade em relação à definição conceitual apresentada? Trata-se, do ponto de vista da metodologia empregada, de uma pesquisa qualitativa de análise de conteúdo de fontes primárias.

\section{PALAVRAS-CHAVE}

Gênero. Sociologia. Livro Didático. PNLD. 


\section{ABSTRACT}

This paper aims to examine how the notion of gender is conceived in sociology textbooks for high school approved by the National Program of Didactic Book (PNLD) through 2015-2017 period. Research questions include: Is the notion of gender conceived in textbooks? Does it appear related to specific issues? What are the theoretical references used in the books to justify the way it's conceived? Are there different treatments or is there a common understanding to the approach taken? Regarding the methodology, a qualitative research of content analysis from primary sources is assumed. It is concluded that most of the books address issues related to gender social relations as well as refer to several researchers on the subject.

\section{KEYWORDS}

Gender. Sociology. Textbook. PNLD.

\section{RESUMEN}

Este artículo analiza la forma en que se trata la noción de género en los libros de texto de sociología para la escuela secundaria aprobados por el Programa Nacional de Libro Didáctico (PNLD) para el trienio 2015-2017. Más precisamente, el trabajo guía preguntas como: ¿está presente la noción de género como contenido en los libros de texto? Si la respuesta es positiva, ¿aparece relacionada con problemas específicos? ¿Cuáles son las referencias teóricas utilizadas en los libros para justificar el enfoque del tema? ¿Existen diferentes formas de tratamiento o existe una homogeneidad en relación con la definición conceptual presentada? Es, desde el punto de vista de la metodología empleada, una investigación cualitativa del análisis de contenido de fuentes primarias.

\section{PALABRAS CLAVE}

género. sociología. libro de texto. PNLD. 


\section{INTRODUÇ̃̃̃o}

A noção de gênero adquiriu visibilidade na atual conjuntura brasileira com a ofensiva de grupos conservadores no campo educacional. Esses grupos têm problematizado a presença, no currículo escolar da educação básica, de práticas educativas orientadas por tal noção, sob a alegação de uma suposta doutrinação de esquerda com base no que denominam de "ideologia de gênero". Essa ideologia, segundo seus defensores, vem permitir a interferência direta da escola na orientação sexual dos educandos, uma vez que põe em questão o "natural desenvolvimento" da personalidade dos adolescentes, personalidade essa que é desenvolvida em "harmonia" com a respectiva "identidade biológica de sexo" de cada indivíduo (PENNA, 2016).

Pelo menos desde meados da década de 2000, com a criação do Movimento Escola Sem Partido, a investida desses grupos tem se materializado, além de intervenções na mídia, em diversos projetos de lei que têm como proposta o banimento da temática de gênero dos documentos oficiais de educação, entre os quais talvez o mais conhecido seja o Projeto de Lei do Senado n 193/2016, recentemente arquivado na câmara, que visava incluir entre as diretrizes e bases da educação nacional o Programa Escola Sem Partido (PESP).

Neste artigo, partindo da hipótese de que não há correspondência entre o conteúdo ensinado nas escolas e essa tal "ideologia de gênero" para o ensino médio, aprovados pelo Programa Nacional do Livro Didático (PNLD) ${ }^{4}$, para o triênio de 2015-2017, abordam o conceito de gênero.

Mais especificamente, i) verificamos se o termo gênero consta nos livros didáticos de Sociologia; ii) se sim, apontamos as definições atribuídas a ele encontradas nesses livros, destacando diferenças conceituais, autores referenciados e teorias relacionadas; iii) por fim, procuramos evidenciar se tal noção aparece articulada à temáticas específicas e, em caso positivo, apontamos quais são elas.

Em vista dos limites espaciais deste artigo, tomamos aqui como objeto de análise tão somente três dos seis livros aprovados pelo PNLD (2015) que tiveram ampla circulação no país, a saber: 1) Sociologia para jovens no século XXI, 2) Sociologia em movimento e 3) Sociologia para o ensino médio. Para realizar a investigação das fontes, utilizamos a técnica de análise de conteúdo categorial (BARDIN, 2002).

Esclareça-se que, no trabalho, não partimos de uma definição prévia acerca do termo gênero. Procuramos, no processo de análise, identificar as passagens, nossa unidade de registro, nas obras, em que se emprega o termo para, em seguida, explicitar a compreensão e o significado que os autores atribuem a ele, em cada uma dessas passagens.

3 Há uma ampla produção teórica sobre o conceito de gênero desenvolvido no campo das ciências sociais. Um breve balanço sobre essa discussão pode ser encontrado em Charles (2010). Para conhecer os principais autores utilizados no Brasil como referência dos trabalhos que fazem uso do conceito de gênero no subcampo da sociologia da educação, ver Carvalho (2011). 4 Trata-se de um programa governamental federal que promove a difusão de livros didáticos nas escolas públicas brasileiras. A edição de 2015 é referente à segunda participação da disciplina no programa. A primeira foi na edição de 2012. 


\section{SOCIOLOGIA PARA JOVENS NO SÉCULO XXI}

O livro Sociologia para jovens no século XXI aparece pela primeira vez entre os livros aprovados pelo PNLD na edição de 2015, que corresponde à segunda edição do programa que contou com a participação da Sociologia - recentemente tornada disciplina obrigatória nos três anos do ensino médio, com a aprovação da Lei no 11.684/2008.

O livro em questão consiste em um trabalho publicado pela editora Imperial Novo Milênio, com autoria de Luiz Fernandes de Oliveira e Ricardo Cesar Rocha da Costa - ambos com formação na área de Sociologia e/ou Ciências Sociais e com experiência em docência no ensino médio. No que se refere ao conteúdo, ele é dividido em três grandes unidades, intituladas, respectivamente: I) Sociedade e conhecimento sociológico, II) Trabalho, política e sociedade e III) Relações sociais contemporâneas.

A noção de gênero, objeto de nossa investigação, é aduzida de diferentes modos em diversas passagens do livro. Ela vai aparecer pela primeira vez no capítulo 2, intitulado Quem sabe faz a hora e não espera acontecer? A socialização dos indivíduos, mais precisamente na seção $A$ sociedade está na cabeça de cada pessoa, na qual são introduzidos alguns dos conceitos de Émile Durkheim. Ela é utilizada na passagem em que se define o conceito de solidariedade mecânica:

A solidariedade mecânica é típica daquelas sociedades nas quais a divisão do trabalho social é pouco diferenciada, se distinguindo somente em alguns papéis sociais, em função do gênero (se homem ou mulher) ou de acordo com a idade. (OLIVEIRA; COSTA, 2013, p. 33-34, grifo nosso).

É possível notar que a noção de gênero, no trecho acima, está relacionada ao binário homemmulher, tomados, estes últimos, como evidentes ao leitor. Caberia perguntar: o que os autores estão a entender por "homem" e "mulher”? Qual é o critério adotado para a definição desses termos? Trata-se de uma referência à constituição biológica do humano? Ou remete também ao histórico-social? Questão sem resposta.

Na ausência de definição a respeito do que seria "gênero", o leitor é levado, portanto, a se defrontar com um terno aparentemente claro, mas que, em verdade, é opaco. A exposição segue com a definição de solidariedade orgânica e com a definição sobre os tipos de suicídio em Durkheim. Não encontramos nenhuma outra menção sobre gênero.

No capítulo 5, Sejam realistas: exijam o impossível identidades sociais e culturais, a noção de gênero aparece pela segunda vez, agora empregada como uma das formas condicionantes - na reflexão do sociólogo Juarez Dayrell - pelas quais a juventude é socialmente construída:

[...] a juventude é uma definição que é socialmente construída, sendo marcada por várias condições sociais, culturais, de gênero e geográficas, ou seja, há jovens de diversas classes, etnias, religiões, com determinados valores, dentre outros aspectos. (OLIVEIRA; COSTA, 2013, p. 33-4, grifo nosso). 
Tal como encontramos no livro, Dayrell toma a noção de gênero como uma condição social que participa, juntamente com outros elementos, do que ele denomina de "condição juvenil” - categoria utilizada em suas pesquisas sobre a relação entre juventude e escolarização. Contudo, curiosamente, não há qualquer pronunciamento acerca do que Dayrell estaria a entender por gênero. Novamente, os leitores são instados a lidar com um termo claro-escuro, que opera mediante de uma pretensa evidência de sentido, na ausência de uma definição científica conceitual.

No capítulo 6, Ser diferente é normal: as diferenças sociais e culturais, a noção aparece em um trecho do artigo Ciladas da diferença, de Flávio Pierucci, que abre o capítulo. 0 trecho selecionado inicia-se com a indagação: “Somos todos iguais ou somos diferentes?”. Linhas à frente, temos:

A começar da segunda metade dos anos 70 , passamos a nos ver envoltos numa atmosfera cultural e ideológica inteiramente nova, na qual parece generalizar-se em ritmo acelerado e perturbador a consciência de que nós, os humanos, somos diferentes de fato, porquanto temos cores na pele e nos olhos, temos sexo e gênero diferentes além de preferências sexuais diferentes, somos diferentes de origem familiar e regional, nas tradições e nas lealdades, temos deuses diferentes [...]. (PIERUCCI apud OLIVEIRA; COSTA, 2013, p. 90, grifo nosso).

Podemos perceber, no trecho acima, que a noção de gênero, diferentemente das menções anteriores, surge demarcada pelas noções de sexo e sexualidade, permitindo-nos supor que Pierucci tem uma concepção na qual distingue tais categorias. Ou seja, gênero, sexo e sexualidade seriam noções que não se infundiriam. Todavia, não observamos o desenvolvimento teórico a esse respeito - uma vez que, como é razoável supor, não se trata do foco do texto do autor.

Convém, ainda, observarmos que a expressão "preferências sexuais", empregada por Pierucci, é objeto de controvérsia no campo dos estudos de gênero, uma vez que, ao lado de noções como "opção" e "orientação sexual", pode ser compreendido enquanto um fenômeno com substância biológica ou psicológica estável e absoluta 5 .

No final do capítulo 8, Ganhava a vida com muito suor e mesmo assim não podia ser pior: o trabalho e as desigualdades sociais na História das sociedades, o termo aparece na discussão sobre mobilidade social. Os autores do livro asseveram que a categoria de mobilidade social deve levar em consideração, entre alguns fatores, as "questões de gênero", presentes na sociedade brasileira (OLIVEIRA; COSTA, 2013, p. 126). No entanto, eles não explicitam, no texto, o que seriam as referidas questões de gênero.

No capítulo 15, Você tem fome de quê? Movimentos sociais ontem e hoje, a noção de gênero é assinalada como um dos elementos, ao lado dos interesses de classe, etnia, orientação sexual e geração, que define e caracteriza os movimentos sociais. Para Oliveira e Costa (2013, p. 233), estes seriam alguns dos elementos pelos quais as relações de opressão são estruturadas em diversos tipos de sociedade.

É no capítulo 18, Gênero e sexualidade no mundo de hoje, constante na unidade 3, que vemos a noção gênero ser abordada de forma mais detida no livro. Segundo os autores, neste capítulo realiza-se "uma reflexão sociológica acerca das relações entre homens e mulheres e entre hete-

5 Para uma crítica à essencialização do conceito de orientação sexual, ver: Sousa Filho (2009). 
rossexuais e não heterossexuais”, relações “marcadas por tensões, preconceitos, discriminações e poder" (OLIVEIRA; COSTA, 2013, p. 285).

A problematização do tema parte de indagações aparentemente simples, mas que dão ensejo à reflexão: “O que nos torna homens ou mulheres?”, “O sexo de uma pessoa depende exclusivamente se ela nasce com genitais e características físicas de homem ou de mulher?” “[...] com os avanços da medicina, quantas vezes encontramos caso de troca de sexos?”, “[...] quantas vezes encontramos homens ou mulheres que se comportam como se pertencessem ao sexo oposto?” (OLIVEIRA; COSTA, 2013, p. 285). Para respondê-las, Oliveira e Costa vão operacionalizar três conceitos: sexo, gênero e sexualidade.

Começam apresentando, ainda na introdução ao capítulo, alguns dos significados atribuídos à palavra sexo. Fundamentam-se nas formulações do antropólogo brasileiro Luiz Mott, que oferece seis definições ao termo (sexo genético, sexo gonodal, sexo genital, sexo psicológico, sexo social e sexo erótico).

Com base nessas definições, Oliveira e Costa destacam que algumas destas definições estão condicionadas ao campo da biologia, enquanto outras ao campo da psicologia e da sociologia. 0 conceito de sexo social, por exemplo, que diz respeito ao "papel de gênero, a forma como cada sociedade vai moldar o comportamento sexual diferenciado dos homens e das mulheres" (OLIVEIRA; COSTA, 2013, p. 286), é conformado por elementos pertinentes ao campo da sociologia.

Na primeira seção do capítulo, que traz como título Sexo e gênero, Oliveira e Costa recorrem às formulações da socióloga estadunidense Deborah Blum e afirmam que a noção de gênero está relacionada às atitudes, sentimentos e comportamentos que condicionam a orientação dos seres humanos pelo masculino ou pelo feminino.

Acionam, em seguida, Joan W. Scott - também socióloga estadunidense, que situa na história a utilização da noção de gênero. Este emerge a partir da década de 1960 por meio da gramática dos movimentos feministas norte-americanos e tinha em vista a contraposição às abordagens biológicas deterministas. Gênero, no sentido empregado por Scott, tem como significado “as relações de caráter cultural que estão sempre presentes - mesmo sem percebermos - nas definições e nas distinções sobre o que é ‘masculino' ou ‘feminino'” (OLIVEIRA; COSTA, 2013, p. 286).

Em cada sociedade, conforme sustentam Oliveira e Costa, existem padrões estabelecidos quanto aos gêneros. Ao agir em conformidade com as expectativas de outros indivíduos quanto aquilo que se considera ser homem ou ser mulher em determinada sociedade, assinalam, aquele que assim o faz adota um "papel de gênero".

Algumas questões interessantes são lançadas: "como nos tornamos do gênero masculino ou feminino? 0 que dizem os sociólogos sobre as diferenças de gênero? As pessoas definem o seu gênero durante o processo de socialização ou já nascem com um papel determinado?" (OLIVEIRA; COSTA, 2013, p. 286). Elas nos permitem, para os autores, compreender a raiz de alguns conflitos sociais vinculados às desigualdades de gênero ou, ainda, ao não cumprimento dos papéis de gênero.

Na seção, Mas, o que é mesmo sexualidade? Oliveira e Costa (2013, p. 287) asseveram que a sexualidade está intimamente ligada à definição de gênero, às identidades constituídas por meio do significado de "ser homem" e "ser mulher" em um tipo dado de sociedade; as diferenças constituídas pelo "ser homem" e "ser mulher" afetam desde a indumentária ao modo como os indivíduos falam, andam, sentem e desejam. 
Oliveira e Costa (2013) explicitam que desde o século XIX as mulheres dão demonstrações coletivas de revolta contra a naturalização de determinados papéis sociais e contra a "dominação masculina”. Nesse sentido, salientam o papel dos movimentos sociais feministas no século XX que colocaram em cena a discussão sobre as questões de gênero e tiveram, assim, grande importância no combate de ideias que naturalizavam comportamentos sociais com base na determinação biológica, mais precisamente fundamentados na diferença entre os sexos.

Em tal concepção, que inclusive é reforçada pela Sociobiologia - segundo os autores -, as mulheres teriam, grosso modo, uma predisposição à docilidade e centrariam suas vidas no cuidado com os filhos enquanto os homens teriam uma predisposição à agressividade e centrariam seu comportamento no provimento da família. São expostas as contribuições de Simone de Beauvoir (1980), em O segundo sexo, sobre feminilidade, que demonstra as relações de poder socialmente construídas existentes em certas ideias socialmente aceitas e que atribuem um lugar subordinado à mulher nas relações sociais.

Ainda segundo os autores, as relações entre homens e mulheres ocorrem de diferentes formas, algumas marcadas pela igualdade dos gêneros e outras marcadas por relações de poder, opressão e submissão. Para Oliveira e Costa (2013), a inserção das mulheres no mercado de trabalho em meados do século XX bem como a presença atuante do movimento feminista proporcionou uma mudança significativa nas relações sociais estabelecidas entre os gêneros no sentido da conquista de uma maior igualdade social. Todavia, a desigualdade ainda persiste.

\section{SOCIOLOGIA EM MOVIMENTO}

Sociologia em movimento, publicado pela editora Moderna, é um livro escrito por várias mãos, dezenove autores ao todo, entre os quais Afrânio Silva, Marcela M. Serrano, Ricardo M. de Ruiz e outros - a maioria com formação na área de ciências sociais e com atuação docente em instituições de ensino público federal situadas no estado do Rio de Janeiro.

Como o livro anterior, consta pela primeira vez entre os livros aprovados no PNDL - Sociologia de 2015. 0 livro é constituído por 6 unidades, divididas em 15 capítulos. A unidade 1 - Sociedade e conhecimento a realidade social como objeto de estudo - (que vai dos capítulos 1 ao 2) é voltada à diferenciação entre conhecimento científico e senso comum, bem como à apresentação da sociologia enquanto ciência. A unidade 2 - Cultura e sociedade: cultura, poder e diversidade nas relações cotidianas - (capítulos 3, 4 e 5) aborda o conceito de cultura, de ideologia, de socialização, raça, etnia e multiculturalismo.

Já a unidade 3 - Relações de poder e movimentos sociais: a luta pelos direitos na sociedade contemporânea - (capítulos 6, 7 e 8) é dedicada à questões relacionados ao poder, à política e ao Estado, assim como à democracia, à cidadania, aos direitos humanos e aos movimentos sociais. A unidade 4 - Mundo do trabalho e desigualdade social - (capítulos 9 e 10) trata de assuntos atinentes ao mundo do trabalho, à estratificação e às desigualdades sociais.

E, a unidade 5 - Globalização e sociedade do século XXI: dilemas e perspectivas - (capítulo 11 e 12) foca as abordagens e as perspectivas sobre o desenvolvimento socioeconômico e sobre o fenômeno 
da globalização. Enquanto a unidade 6 - A vida nas cidades do século XXI - questões centrais de uma sociedade em construção - (capítulos 13, 14 e 15) apresenta temáticas relacionadas às sociedades contemporâneas, entre as quais, sexualidade, questões de gênero e questões acerca do meio ambiente.

A noção de gênero vai aparecer já no capítulo 1 - Produção de conhecimento: uma característica fundamental das sociedades humanas -, mais exatamente no final da seção 7, A Sociologia e a interpretação da sociedade do século XXI. Ela consta como uma das questões pertinentes à vida cotidiana atual e que, por isso, é tema de estudo das Ciências Sociais. 0 termo, no mesmo texto, é ainda tomado como uma das variáveis a partir da qual pesquisas são realizadas, podendo inclusive, segundo os autores, se tornar base para políticas públicas e para reflexões a serem realizadas com os jovens sobre seu modo de vida (SILVA et al., 2013, p. 27).

No capítulo 3 - Cultura e Ideologia -, na seção 4, Cultura, identidade, rede e fluxos no século XXI, ela aparece como um dos critérios pelos quais são construídas identidades sociais, geradora de demandas específicas, diferindo dos marcadores constituintes das identidades coletivas características da modernidade, como classe social ou nacionalidade. Segundo Silva e outros autores (2013, p. 74), os atores sociais pertencentes a coletivos sociais pautados em marcadores como gênero, etnia e outros compartilham de símbolos (indumentária, estilo de vida, gostos etc.) que permitem o contraste com outros coletivos.

No capítulo 5, Raça, etnia e multiculturalismo, emprega-se a expressão preconceito de gênero. 0 preconceito de gênero aparece ao lado de fenômenos como os preconceitos de classe, de crenças, de orientação sexual, de nacionalidade, de etnia e de cultura. Isso para sustentar, em seguida, que tais preconceitos dão base para práticas discriminatórias e segregacionistas:

Essas práticas, que expressam estruturas hierárquicas socialmente construídas, valorizam certos grupos sociais em detrimento de outros. Assim, os métodos de discriminação e segregação materializam processos ideológicos fundamentados em preconceitos que refletem a hegemonia de um grupo social e a consequente subordinação dos demais. (SILVA et al., 2013, p. 104).

Ao se analisar o trecho acima, nota-se que a noção de gênero, assim como as outras referidas, passa a orbitar em torno da problemática da desigualdade social. A discriminação e o preconceito são atribuídos às estruturas hierárquicas reveladoras das assimetrias entre os grupos constituintes da sociedade. Na subseção Discriminação, novamente se emprega a expressão preconceito de gênero.

Mas, agora, são citadas algumas formas pelas quais o preconceito de gênero se expressa socialmente, a saber: pela discriminação que as mulheres sofrem no mercado de trabalho em relação aos homens no que diz respeito à média salarial inferior recebida, aos cargos de chefia e de maior prestígio ocupados. 0 mercado de trabalho se conforma segmentado, nesse sentido, "conforme o gênero" (SILVA et al., 2013, p. 109).

Na subseção Segregação, que se encontra no mesmo capítulo, lemos que a segregação é praticada de forma consciente e institucional com base em ideologias que pregam a superioridade de gênero, etnia, classe social ou nacionalidade (SILVA et al., 2013, p. 110). Em todas as aparições do termo, poderíamos perguntar: gênero seria uma noção homóloga à noção de sexo? Como observado, nada se diz até aqui sobre o significado atribuído ao termo, malgrado a sua operacionalização. 
No capítulo 10, Estratificação e desigualdades sociais, na seção 4, ao tratar das intepretações sobre a pobreza no Brasil, os autores destacam as principais formas de desigualdade existentes nas sociedades contemporâneas e afirmam que elas estão agrupadas por critérios de classe, de gênero, de raça (ou etnia) e de orientação sexual. Segundo Silva e outros autores (2013, p. 241), essas desigualdades não são percebidas devido ao imaginário coletivo, constituído por "um modelo de indivíduo e sociedade no qual as diferenças culturais e biológicas têm função hierarquizadora em espaços distintos da vida social".

Um exemplo dado é o machismo, fenômeno fundado no imaginário coletivo segundo o qual as mulheres devem se subordinar aos homens. A relação social estabelecida entre homens e mulheres é designada pela expressão relações de gênero, como se pode depreender do trecho: “É assim, por exemplo, que a mulher é percebida como naturalmente inferior ao homem. Essa concepção, base do machismo presente nas relações de gênero, coloca a mulher em desvantagem nas diversas formas de relação" (SILVA et al., 2013, p. 241).

Essa desigualdade nas relações de gênero pode estar imbricada à outras formas de desigualdade, como à de raça (etnia) e à de inserção no mercado de trabalho.

Para mostrar a materialização da desigualdade nas relações de gênero, os autores citam uma passagem do Código Civil brasileiro de 1916, Lei n 3.071/16, que regulava as relações jurídicas de ordem privada. A referida lei faz referência aos "direitos do marido", enquanto "chefe da sociedade conjugal”, sobre a mulher. Entre esses direitos, estava o direito de "autorizar a profissão da mulher e a sua residência fora do teto conjugal" 6 .

Conforme Silva e outros autores (2013, p. 241) trata-se de “[...] um documento histórico que oficializa a desigualdade entre os gêneros, um traço exemplar da sociedade patriarcal”. Em seguida, são apresentados índices mundiais e dados sobre a realidade brasileira, como participação no mercado de trabalho e rendimento médio mensal de homens e mulheres, que demonstram a desigualdade de gênero.

Na seção Desigualdades entre os jovens, a problemática da desigualdade de gênero emerge relacionada aos estudos sobre juventude. Aponta-se que as meninas dispendem, em média, mais tempo (12,5 horas semanais) em tarefas domésticas do que os meninos (7,9 horas semanais). E, no que se refere à agressão contra os jovens, elas são as principais vítimas (SILVA et al., 2013, p. 248).

No capítulo 14, Gênero e sexualidade, como o próprio título indica, a noção de gênero é tomada como objeto de estudo, recebendo embasamento teórico. 0 capítulo faz parte da unidade $6, A$ vida nas cidades do século XXI - questões centrais de uma sociedade em construção.

Entre os objetivos do capítulo estão:

Compreender como a definição cultural e histórica de gênero e de orientação sexual é construída socialmente; Reconhecer as variações de gênero e sexualidade em diferentes culturas e momentos históricos; Identificar o caráter de gênero entre as desigualdades sociais existentes no mundo; Relacionar a experiência subjetiva de identidade de gênero às lutas políticas a favor da diversidade e contra o preconceito e discriminação. (SILVA et al., 2013, p. 336, grifos nossos).

6 BRASIL. Lei n. 3.071, de janeiro de 1916. Código Civil dos Estados Unidos do Brasil. Disponível em: <http://www.planalto. gov.br/ccivil_03/leis/L3071.htm>. Acesso em: 2 jun. 2017. 
Os autores lançam a seguinte "questão motivadora" para abordar o tema: como construir uma sociedade que respeite a diversidade e garanta a igualdade de direitos e oportunidades entre homens e mulheres se há a persistência da cultura machista no país? Depreende-se que é com base na problemática da desigualdade social e do poder que a noção de gênero é significada.

Na página de abertura do capítulo, encontramos a definição atribuída à noção de gênero:

Gênero é a identidade assumida ou atribuída de acordo com o sexo ou com o papel exercido socialmente. Essas identidades, que são construtos sociais, vêm sendo questionadas historicamente; nas Ciências Sociais, as "questões de gênero" referem-se às desigualdades de condições entre homens, mulheres e transgêneros. (SILVA et al., 2013, p. 336).

Na seção 1, Primeiras palavras, a expressão “desigualdade de gênero" é empregada ao lado de "homofobia" e "discriminação baseada em critérios sexuais", frisando-se que tais fenômenos persistem na sociedade brasileira. Segundo Silva e outros autores (2013, p. 337)., "a discriminação e a violência contra a mulher estão inseridas em um tipo específico de desigualdade, relacionado ao que ficou conhecido nas Ciências Humanas como questões de gênero".

Afirma-se na seção 2, O que é gênero e sexualidade?E, para se compreender as questões de gênero é preciso diferenciar gênero, sexo e sexualidade. Partindo desses marcadores, a noção de sexo é relacionada "às características físicas de um ser humano: aos órgãos genitais e às formas do corpo [...]". Já a noção de gênero, diz-se, na sociologia, "tem a função de classificar o masculino e o feminino nas sociedades humanas" (SILVA, 2013, p. 338).

Todavia, segue a advertência: "essa classificação não se fundamenta em um princípio evolutivo, biológico ou morfológico, e sim em uma construção social” (SILVA, 2013, p. 338). Logo em seguida, Silva e outros autores (2013, p. 340) introduzem a noção de identidade de gênero, a qual é influenciada por convenções sociais, estereótipos e expectativas geradas ao longo do processo de socialização:

A sexualidade está vinculada à orientação do desejo sexual e afetivo e à representação social ou subjetiva da identidade de gênero. Portanto, não é determinada pela constituição biológica do indivíduo. 0 conceito de gênero está associado à vivência da sexualidade no ambiente sociocultural. [...] É nesse sentido que algumas pessoas do sexo masculino apresentam uma identidade de gênero que condiz com o que o grupo social classificaria como comportamento "feminino".

Note-se, no trecho acima, a relação não necessária entre sexo e identidade de gênero. Mais à frente, os autores sustentam que:

As possibilidades sociais de construção de identidade de gênero são muitas e extrapolam os padrões rígidos estabelecidos pela tradição. Em uma sociedade, quanto mais restritos são os estereótipos de gênero, menor é a tolerância à diversidade e mais duras são as punições (simbólicas, jurídicas e, por vezes, físicas) àqueles que não se encaixam no quadro das relações previstas pelo grupo. (SILVA et al., 2013, p. 340). 
Na seção Gênero, sexualidade, poder e comportamento, os autores apontam que as questões relacionadas à desigualdade de gênero estão diretamente ligadas à existência de fenômenos como o patriarcalismo e o androcentrismo. Nesse sentido, estão ligadas às questões de poder, de "dominação com base no gênero" enquanto construções histórico-sociais.

Por fim, explicitam que, no decorrer do século XX, ocorreram mudanças importantes nas relações entre o feminino e o masculino. Tais mudanças podem ser exemplificadas na elevação das taxas da presença das mulheres no mercado de trabalho, na conquista da igualdade de direitos civis e políticos entre os diferentes sexos, entre outros, até então inexistentes.

\section{SOCIOLOGIA PARA O ENSINO MÉDIO}

Sociologia para o Ensino Médio, publicado pela editora Saraiva, é um dos poucos livros aprovados nas duas edições do PNLD - Sociologia. Foi escrito por Nelson Dacio Tomazi, professor universitário aposentado e conhecido militante na luta pela defesa do ensino de Sociologia no país. Seu livro é constituído por unidades - sete ao todo -, sendo cada uma delas compostas por três ou quatro capítulos.

No total, o livro possui vinte e três capítulos. A unidade 1, $A$ sociedade dos indivíduos, aborda temas como a figura do indivíduo na modernidade, o processo de socialização e as relações entre indivíduo e sociedade na visão dos clássicos, como Marx, Durkheim, Weber, Elias e Bourdieu. A unidade 2, Trabalho e sociedade, trata das formas que o trabalho assume nos diferentes tipos de sociedade (tribal, escravista e moderna), dando à produção na sociedade capitalista moderna e à situação do trabalho no Brasil.

Já a unidade 3 , A estrutura social e as desigualdades, trata de conceitos que voltados à reflexão a respeito da estrutura das desigualdades sociais no Brasil e no mundo. A unidade 4, Poder, política e Estado, apresenta os tipos de Estado e de regimes políticos, os modelos de desenvolvimento de políticas estatais, bem como aborda a configuração do processo político no Brasil. A unidade 5, Direitos, cidadania e movimentos sociais, volta-se aos conceitos de cidadania, de direitos civis, políticos e sociais, ao estudo dos movimentos sociais contemporâneos e dos movimentos sociais no Brasil.

E, as unidades 6, Cultura e ideologia, centra-se no conceito de cultura, de etnocentrismo, de ideologia e de indústria cultural; a unidade 7, Mudança e transformação social, é pautada em assuntos relacionados à modernização, ao desenvolvimento econômico e às transformações sociais no mundo e no Brasil. Após as sete unidades, tem-se ainda o apêndice, denominado de História da Sociologia: pressupostos, origem e desenvolvimento, que trata das transformações ocorridas no ocidente que ensejaram a criação e o desenvolvimento da Sociologia enquanto ciência na história.

Conforme o exposto acima, é possível observar que nenhuma das unidades é voltada ao estudo da noção de gênero - não sendo ela também assunto dominante em nenhum de seus capítulos. Mas, ainda assim, é possível encontrar, em alguns trechos, a presença do emprego da noção de gênero no tratamento de outros temas.

No complemento que consta no final do capítulo 8 , intitulado $A$ sociedade capitalista e as classes sociais, constante na unidade 3 , Tomazi explicita os "Cenários das desigualdades" no mundo 
e, então, aborda brevemente a temática da desigualdade entre homens e mulheres, onde podemos encontrar a utilização da expressão desigualdade de gênero. Segundo Tomazi (2010, p. 84), essa desigualdade manifesta-se na inserção no mercado de trabalho, no nível salarial, no acesso à educação, à saúde e nos índices de violência sexual.

No capítulo 9, As desigualdades sociais no Brasil, a noção de gênero aparece novamente só que desta vez relacionada às desigualdades sociais que marcam a formação social brasileira. Ela é utilizada na seção Mercado de trabalho e condições de vida, quando Tomazi afirma que, na década de 1990, questões relacionadas ao emprego e às condições de vida dos trabalhadores pobres passam a compor as análises sobre as desigualdades sociais no país; a noção de gênero é utilizada no interior desse contexto, na passagem: "A questão de gênero ganhou espaço, destacando principalmente a situação desigual das mulheres em relação à dos homens” (TOMAZI, 2010, p. 90).

No final do capítulo, no texto $O$ abismo brasileiro entre brancos e negros, a noção novamente aparece, agora em dois momentos. Primeiro, no título da pesquisa do Instituto de Pesquisa Econômica Aplicada (IPEA): Retratos das Desigualdades de Gênero e Raça. Segundo, em uma citação da afirmação do pesquisador Jorge Abrahão sobre a relação de não correspondência entre crescimento econômico e diminuição da desigualdade entre negros e brancos: “As desigualdades não diminuem tão rapidamente quanto o crescimento do país porque as políticas públicas fazem recorte por renda e não por gênero ou raça” (TOMAZI, 2010, p.92).

Note-se que, tanto no primeiro quanto no segundo, o termo gênero aparece por estar associado à noção de raça, não sendo, portanto, o foco da abordagem de Tomazi, que está a tratar da desigualdade entre brancos e negros.

A noção de gênero vai ser empregada com objetivo visado na atividade de pesquisa proposta ao final do capítulo. Nela, solicita-se aos alunos que:

Em grupo, procurem fazer um levantamento de opiniões de pessoas de diferentes idades, sexo, etnia e condições sociais, sobre a questão das desigualdades no Brasil. A partir dessas explicações, identifiquem os possíveis preconceitos de classe, gênero e raça. (TOMAZI, 2010, p. 95).

No capítulo 15, Os movimentos sociais, a noção de gênero é acionada na reflexão sobre "o movimento feminista" [sic], que, segundo o autor, teve um papel importante na luta por direitos políticos, civis e sociais, bem como no questionamento dos fundamentos culturais das desigualdades de gênero. Para Tomazi, a discussão a respeito do lugar subordinado ocupado pelas mulheres em diferentes sociedades vem desde o século XVIII. Faz menção a figuras como Olympe de Gouges (ativista política feminista francesa guilhotinada em 1793), Mary Wollstonecraft (filósofa que, em 1792, publica o ensaio Em defesa dos direitos da mulher), Jeanne Deroin e Flora Tristán (líderes operárias e referências para o movimento feminista).

Ainda, a estudos como os de Betty Friedan (A mística feminina), Kate Millet (Política sexual) e Juliet Mitchell (A condição da mulher). Por fim, destaca a diversificação das lutas que integram o movimento feminista na atualidade, que inclui temas como "crítica a sociedade patriarcal, baseada na 
dominação do homem"; "a igualdade de condições e de salários"; "a especificidade da visão feminina do mundo em todas as áreas do conhecimento"; "a discussão sobre a identidade corporal e a sexualidade feminina”, entre outros (TOMAZI, 2010, p. 149-150).

No apêndice, a noção de gênero é empregada pela última vez. Mais exatamente na subseção $D i$ versificação da disciplina, da seção A sociologia no Brasil. Gênero aparece, juntamente com violência, religião, juventude, comunicação e indústria cultural, entre as preocupações e temáticas que passaram a atrair o interesse de estudiosos a partir da década de 1980, com a expansão dos cursos de pós-graduação em Sociologia e Ciências Sociais em território nacional (TOMAZI, 2010, p. 225).

Não obstante esteja presente no livro, a noção de gênero não recebe tratamento teórico detido pelo autor.

\section{CONCLUSÃO}

Ao analisar os dois livros didáticos acima, podemos concluir que, no que se refere a presença da noção de gênero, todos fazem emprego do termo, não obstante no primeiro e no segundo constarem um tratamento teórico mais detido, o que se nota pelos capítulos dedicados ao tratamento do conceito/tema; observamos, ao mapear a utilização do termo gênero, que apenas o primeiro e o segundo prezam por uma definição teórica fundamentada no trabalho de especialistas sobre o assunto, destacando os autores e as teorias relacionadas. 0 terceiro livro opta por uma utilização prática, abdicando do trabalho de conceituação. Todavia, situa a temática das "questões de gênero" na história e cita diversos autores e personalidades históricas - em um trabalho de contextualização.

$E$, o conceito de gênero é mobilizado nos três livros para a compreensão de fenômenos sociais, como a desigualdade de gênero, evidenciada na posição subordinada que as mulheres ainda ocupam em diversas instâncias. Os três livros trazem dados atuais a respeito disso.

Também, é possível notar, ainda, que a noção de gênero é relacionada a outras noções, que lhe dão sentido, bem como se observa a referência a formulações de estudiosos e pesquisadores consagrados em diferentes campos da ciência.

Em tais tratamentos, não se verificou qualquer vinculação político-partidária e/ou doutrinária. 0 que demonstram, diferentemente daqueles que são contrários à sua utilização, possibilidade de empregar o conceito de gênero para a análise e compreensão da realidade social.

\section{REFERÊNCIAS}

BARDIN, Laurence. Análise de conteúdo. Lisboa: Edições 70, 2002.

BRASIL. Guia de livros didáticos: PNLD 2015: Sociologia: ensino médio. Brasília: Ministério da Educação, Secretaria de Educação Básica, 2014. 
CARVALHO, Marília P. O conceito de gênero: uma leitura com base nos trabalhos do GT Sociologia da Educação da ANPEd (1999-2009). Revista Brasileira de Educação, v. 16, n. 46, p. 99-117, 2011.

CHARLES, Nickie. Gênero. In:SCOTT, J. (Org.).

Sociologia: conceitos-chave. Rio de Janeiro: Zahar, 2010.

SOUSA FILHO, Alípio de. A política do conceito: subversiva ou conservadora? crítica à essencialização do conceito de orientação sexual. Bagoas - Estudos gays: gêneros e sexualidades, v. 3, n. 4, 27 nov. 2012.

PENNA, Fernado. A. Programa "Escola Sem Partido": uma ameaça à educação emancipadora. In: GABRIEL, C. T.; MONTEIRO, A. M.; MARTINS, M. L. B. (Org.). Narrativas do Rio de Janeiro nas aulas de história. Rio de Janeiro: Mauad X, 2016. p. 43-58

\section{OLIVEIRA, L. F; COSTA, R. C. R. Sociologia para} jovens do século XXI. 3. ed. Rio de Janeiro: Imperial Novo Milênio, 2013.

SILVA, Afrânio et al. Sociologia em movimento. São Paulo: Moderna, 2013.

TOMAZI, Nelson D. Sociologia para o ensino médio. 2. ed. São Paulo: Saraiva, 2010.

1 Professor de Sociologia do Instituto Federal de Educação, Ciência e Tecnologia de São Paulo (IFSP) - campus Birigui. Doutorando e mestre pelo Programa de Pós-graduação em Ciências Sociais da UNESP - campus de Marília; Especialista em Ensino de Sociologia no ensino médio pela Universidade Federal de São João del-Rei (UFSJ); Licenciado em Ciências Sociais pela UNESP. E-mail: rkhidaka@ifsp.edu.br

2 Graduanda em Pedagogia pela UniToledo; Técnica em Administração pelo Instituto Federal de Educação, Ciências e Tecnologia de São Paulo - IFSP.

E-mail: gabrielaabdo6@gmail.com

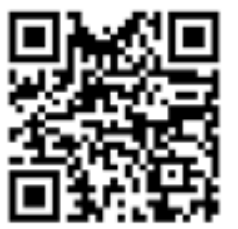

A autenticidade desse artigo pode ser conferida no site https://periodicos. set.edu.br
Como citar este artigo:

ROMEO, Andrea. Lo special account del fenomeno religioso nel dibattito nordamericano. Argumenta Journal Law, Jacarezinho - PR, Brasil, n. 29., 2018, p. 15-48. DOI: $10.17564 / 2316-3828.2018 v 7 n 1 p 13-24$

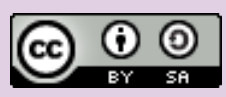

Este artigo é licenciado na modalidade acesso abertosob a Atribuição-Compartilhalgual CC BY-SA 